\title{
Implementasi Shambatan Application Guna Mengoptimalkan Program Bantuan Dana Untuk Pemberdayaan Ekonomi Masyarakat Desa Kecamatan Lumbir
}

\author{
Muhamad Awiet Wiedanto Prasetyo ${ }^{1}$, Muhamad Rezha Riaqia Putra ${ }^{2}$ \\ 1,2Program Studi Sistem Informasi Fakultas Ilmu Komputer Universitas Amikom Purwokerto \\ Jl. Let. Jend. Pol. Soemarto, Purwangera, Purwokerto, telp. 0821623321 \\ e-mail: ${ }^{1}$ mawp@amikompurwokerto.ac.id, ${ }^{2}$ muhamadrezha@gmail.com
}

\begin{abstract}
Abstrak
Permasalahan yang terjadi ketua kelompok harus datang dengan membawa persyaratan administrasi pengajuan proposal pinjaman bantuan dana pada BKAD Satria Mandiri, tujuan penulis adalah mengimplementasikan Shambatan Application untuk mengoptimalisasikan program bantuan dana guna pemberdayaan ekonomi masyarakat desa. Proses pembuatan Shambatan Application menggunakan Metode Viewpoint Oriented Requirement Definition (VORD), salah satu diantaranya adalah menerapkan Shambatan Application. Sebuah sistem yang menghasilkan menu mengolah data proposal anggota nantinya petugas dengan cara input data mampu mengetahui anggota baru atau lama yang memiliki kategori kolektibiltas 1 sampai dengan 6 kemudian memvalidasi hasil dari proposal tersebut. Terdapat menu transaksi kredit yang dapat dilihat oleh para anggota dan tidak perlu khawatir kembali. Menu laporan yang salah satunya menghasilkan neraca keuangan secara automatis, untuk dilaporkan ke Dinas Sosial Kabupaten Banyumas.
\end{abstract}

Kata kunci: BKAD, VORD, Shambatan Application.

\begin{abstract}
Problems that occur group leaders must come with an administrative requirement to submit proposals for loan aid funds at BKAD Satria Mandiri, and author goal is to implement the Sambhatan Application to optimise the financial assistance program for economic empowerment of rural communities. The process of making Shambatan Application uses the Viewpoint Oriented Requirement Definition (VORD), one of which is applying the Shambatan Application. A system that produces a menu to process members and staff proposal data using data input can find out new or old members who have collectables 1 to 6. There are credit transaction menus that can be seen by members and need not worry again. One of the menu reports is generated a balance sheet automatically, to be reported to the Social Official Banyumas Regency.
\end{abstract}

Keywords: BKAD, VORD, Shambatan Application.

\section{Pendahuluan}

Koperasi memiliki arti penting dalam membangun perekonomian nasional, dengan kata lain perekonomian dirumuskan guna usaha bersama berdasarkan atas asas kekeluargan [1]. Awal terbentuknya koperasi merupakan kumpulan orang-orang yang memiliki tingkat perekonomian kategori bawah, akan tetapi ada pula berekonomi tinggi. Dengan melalui koperasi mereka bersama-sama mempunyai tujuan untuk meningkatkan kesejahteraan ekonomi dan sosial. Hal ini karena atas dasar koperasi sesuai Bangsa Indonesia yang bersifat gotong royong dan kekeluargaan [2]. Koperasi seharusnya mempunyai ruang gerak dan kesempatan 
lebih luas untuk menyangkut kepentingan ekonomi rakyat dengan semakin perkembangan modern yang sangat pesat dan kearah masa mendatang. Karena perekonomian berperan mewujudkan masyarakat yang adil dan makmur berlandaskan Pancasila dan Undang-Undang Dasar 1945, dalam perekonomian skala nasional disusun sebagai usaha bersama berdasarkan asas kekeluargaan dan demokrasi ekonomi [3].

Koperasi yang berfungsi membangun dan mengembangkan potensi para anggota khususnya dan masyarakat pada umumnya, dengan tujuan meningkatkan kesejahteraan dari segi ekonomi dan sosial. Kemudian mengupayakan kualitas hidup pada masyarakat yang lebih baik masa mendatang, memperkuat dari segi ekonomi rakyat guna untuk dasar kekuatan dan ketahanan perekonomian nasional dan koperasi sebagai soko gurunya dengan cara usaha bersama berdasarkan atas asas kekeluargaan dan demokrasi dari segi ekonomi [4]. Koperasi merupakan salah satu usaha ekonomi rakyat yang memberi kemudahan anggotanya untuk memperoleh modal usaha, memberikan keuntungan dengan sisa hasil usaha, mengembangkan usaha anggota dan menghindari kegiatan peminjaman ke pihak rentenir yang memberikan kemudahan dalam proses peminjaman namun suku bunga pinjaman sangat besar [5]. Langkah kedepannya untuk memberikan pelayanan yang baik dan menguntungkan bagi para anggota adalah dengan cara memberikan produk barang atau jasa yang berkualitas tinggi dan pelayanan yang mampu memberikan kepuasan tersendiri kepada para anggota.

Seperti penelitian yang sudah ada kualitas pelayanan yang baik memiliki pengaruh signifikan terhadap kepuasan anggota koperasi yang menimbulkan rasa kepuasan tersendiri bagi anggota Koperasi Jasa keuangan Syariah KUM 3 Rahmat Surabaya [6]. Cara paling efektif pengambilan keputusan dengan memanfaatkan teknologi informasi yang mampu menghasilkan sistem informasi untuk instansi atau organisasi perusahaan. Kemudian penelitian sekarang difokuskan untuk menganalisa, merancang dan membangun sebuah sistem informasi seperti aplikasi dengan platform website yang sesuai sehingga membantu organisasi melakukan proses bisnis agar lebih efektif. Sistem informasi manajemen adalah kumpulan dari manusia dan sumber daya modal didalam suatu instansi yang bertanggungjawab mengumpulkan dan mengolah data untuk menghasilkan informasi yang berguna untuk semua tingkatan manajemen [7]. Sistem informasi digunakan koperasi dapat membantu pengelolaan data, Badan Kerjasama Antar Desa (BKAD) Satria Mandiri Kecamatan Lumbir sebagai salah satu lembaga yang bergerak dalam Bidang Jasa memberikan bantuan dana kepada usaha-usaha kecil yang membutuhkan pinjaman dana dalam upaya mendukung pemerintah meningkatkan Bidang Usaha Mandiri Kecil dan Menengah (UMKM). UMKM merupakan suatu usaha yang potensial bagi perkembangan perekonomian Indonesia sehingga dalam pelaksanaannya perlu peningkatan pembangunan ekonomi masyarakat.

Berdasarkan hasil wawancara dengan Bapak Suroso (Ketua BKAD) "Sumber keuangan kami berasal dari pemerintah, kemudian disalurkan kepada masyarakat yang nantinya wajib mengajukan proposal pinjaman dana sebagai salah satu syarat administrasi, akan tetapi apabila pada proposal tersebut masih ada nama yang memiliki tanggungan angsuran tidak dapat diajukan sebagai peminjam. Artinya adalah anggota harus sudah lunas dari segala tanggungan yang ada pada BKAD Satria Mandiri, kemudian proposal yang tercantum nama ketua beserta anggota yang harus dalam satu desa wilayah Kecamatan Lumbir dan proposal tersebut diharuskan berkelompok bukan individu". Dari kegiatan BKAD Satria Mandiri berlangsung terdapat permasalahan seperti ketua anggota kelompok harus dating dengan membawa berkasberkas yang dibutuhkan sebagai persyaratan pengajuan proposal pinjaman bantuan, solusi yang ditawarkan oleh pihak instansi dengan cara melakukan survey langsung untuk mengecek dan membawa persyaratan. Dengan solusi yang ditawarkan terdapat permasalah seperti fotocopy KTP atau fotocopy KK, hilang ditengah jalan atau pengajuan surat perjannjian kontrak rusak 
terkena air hujan, mengingat saat ini memasuki musim penghujan. Kemudian banyaknya data yang tidak tersimpan pada satu file (Microsoft Excel), cara tersebut juga akan menyulitkan pihak instansi mencari data keuangan yang tersimpan pada periode tahun berbeda untuk membuat laporan hasil neraca tahunan yang akan diserahkan Dinas Sosial Kabupaten Banyumas. Perkembangan sistem informasi menjadi topik yang hangat diperbincangkan dan merupakan faktor yang penting bagi sebuah perusahaan atau instansi untuk dapat bersaing dalam perekonomian dan meningkatkan efisiensi atau efektivitas bisnis dalam instansi, salah satunya pada sektor koperasi yang mampu memanfaatkan teknologi informasi atau sistem informasi.

Teknologi informasi sudah menjadi kebutuhan utama sebagai alat penunjang dari proses bisnis setiap instansi seperti penelitian yang relevan dengan memanfaatkan teknologi informasi dalam proses pencarian, penginputan dan pengolahan data serta transaksi yang berlangsung didalam Unit Usaha Waserda Koperasi Karyawan PT. Multi Karya Usaha menjadi lebih baik [8].

Penelitian relevan selanjutnya adalam pada Koperasi SMKN 15 Bandung yang menghasilkan sistem informasi aplikasi koperasi berbasis website, petugas melakukan validasi setelah proposal masuk dan bias dinyatakan diterima atau ditolak serta terdapat kekurangan berupa laporan pemasukan dan pengeluaran belum masuk pada aplikasi yang telah dibuat [9]. Untuk penelitian sekarang terdapat juga proses pencarian dapat diketahui melalui kode nomor pendaftaran, ketua anggota dan nama desa. Kemudian pada Shambatan Application terdapat pengolahan data calon anggota dengan cara melihat isi proposal, total dana yang diajukan dan masuk kategori kolektibilas 1 sampai dengan 6 yang khususnya anggota lama yang mengajukan proposal kembali. Shambatan Application terdapat menu laporan yang secara automatis menghitung neraca keuangan untuk dilaporlan ke Dinas Sosial Kabupaten Banyumas.

Solusi yang ditawarkan oleh peneliti menggunakan Metode Viewpoint Oriented Requierement Definition nantinya menganalisa kebutuhan perangkat lunak berdasarkan sudut pandang pengguna agar terciptanya aplikasi yang mampu membantu kinerja para petugas BKAD Satria Mandiri dalam menyajikan laporan kepada pimpinan maupun Dinas Sosial Kabupaten Banyumas dan memberikan informasi kepada para anggota secara cepat. Kelebihan dari metode ini adalah terstruktur untuk mengambil data, dokumentasi data, analisa data untuk memspesifikasikan sudut pandang berdasarkan kebutuhan pengguna [10].

\section{Metode Penelitian}

\subsection{Konsep Penelitian}

Dalam penyusunan penelitian ini, penulis menyusun kerangka kerja penelitian terlebih dahulu yang menjadi acuan penulis dalam menyusun penelitian. Kerangka kerja merupakan langkah-langkah yang dilakukan penulis dalam penyelesaian masalah yang akan dijelaskan. Adapun kerangka kerja penelitian yang digunakan seperti pada Gambar 3. Kerangka Kerja Penelitian:

Kegiatan

Keluaran

\begin{tabular}{|c|c|}
\hline Studi Literatur & Pemahaman tentang teori \& konsep \\
\hline Pengumpulan Data & Data dan informasi yang dibutuhkan \\
\hline Pengembangan Sistem & Daftar masalah yang membutuhkan solusi \\
\hline Pembuatan Laporan & Viewpoint Oriented Requirement Definition \\
\hline
\end{tabular}

Gambar 3. Kerangka Penelitian 
Berdasarkan Gambar 3. Kerangka Kerja Penelitian, maka dapat diuraikan Studi Literatur pada tahap ini mencari dan memahami landasan-landasan teori yang diperoleh dari berbagai buku juga internet berupa jurnal atau prosiding penelitian untuk melengkapi perbendaharaan konsep teori, sehingga memiliki landasan dan keilmuan yang baik dan sesuai. Pengumpulan data, penulis mengumpulkan data dengan metode wawancara, dokumentasi dan observasi untuk melakukan pengamatan dan analisa sehingga mendapatkan data dan informasi yang dibutuhkan oleh peneliti. Analisis Sistem, penulis melakukan identifikasi masalah pada sistem yang sedang berjalan pada koperasi sebagai objek penelitian dengan penggunaan sistem secara manual dan belum otomatis terhubung yang digunakan dengan menggunakan aplikasi Microsoft Excel.

Pengembangan Sistem Setelah melakukan analisis pada sistem yang sedang berjalan, berdasarkan pada Gambar 4. DFD Shambatan Application, menggambarkan bagaimana sistem terhubung dengan pengguna yang berkepentingan atau membutuhkan informasi. Model bentuk kedua adalah logikal model yang digambarkan dengan diagram arus data. Model ini menjelaskan kepada user bagaimana nantinya fungsi-fungsi sistem informasi secara logika akan bekerja. Sketsa dari physical sistem dapat menunjukkan kepada user bagaimana nantinya sistem secara fisik akan diterapkan. Pembuatan Laporan Pada tahap pembuatan laporan, penulis membuat laporan yang disusun berdasarkan hasil penelitian dengan menggunakan teknik pengumpulan data primer dan sekunder, sehingga mejadi laporan penelitian yang dapat memberikan gambaran secara utuh tentang sistem yang sedang dibangun.

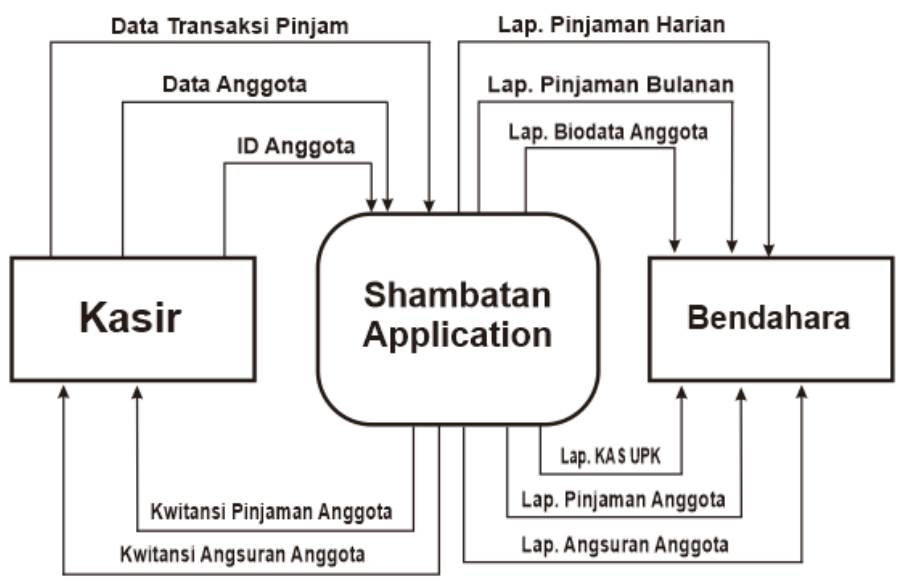

Gambar 4. DFD Shambatan Application

\subsection{Metode Pengumpuan Data}

Instrumen penelitian yang digunakan adalah wawancara teknik pengumpulan data apabila peneliti ingin melakukan studi pendahuluan untuk menemukan permasalahan yang harus diteliti dan peneliti dapat mengetahui permasalahan responden yang bisa dialami. Peneliti melakukan wawancara kepada seluruh karyawan BKAD Satria Mandiri dan beberapa kelompok yang melakukan angsuran kredit. Hasilnya terdapat kendala untuk mengetahui total angsuran yang sudah dilakukan oleh kelompok dan para karyawan kesulitan untuk membuat laporan neraca dari tahun ke tahun yang diakibatkan berbeda file penyimpanannya, dokumentasi Teknik pengumpulan data dengan cara mengkaji dan mengolah data dari dokumen-dokumen yang sudah ada sebelumnya dan mendukung data peneliti. Peneliti mengumpulkan berkas proposal pengajuan, transaksi dan lainnya. Dengan berkas file yang berbeda, peneliti memberikan solusi mengimplementasikan Shambatan Application untuk mengoptimalkan penyaluran dana desa 
dan observasi Teknik pengumpulan data meneliti tentang perilaku makhluk hidup, proses kerja dan gejala-gejala yang terjadi pada alam sekitar atau pendekatan untuk mendapatkan data primer dengan cara mengamati langsung obyek datanya. Peneliti mengamati proses bisnis Satria Mandiri dengan cara mengikuti alur pengajuan proposal peminjaman hingga proses selesainya angsuran kredit. Insturmen penelitian digunakan untuk mengukur nilai variabel yang diteliti dengan menentukan jumlah instrumen yang akan digunakan pada penelitian[11].

\subsection{Metode Pengembangan Sistem}

Metode Viewpoint Oriented Requirement Definition yang menggambarkan kebutuhan sistem sebagai suatu layanan terhadap viewpoint. Berdasarkan pada Gambar 5. Alur proses VORD, memiliki tiga tahapan utama [12] yaitu Viewpoint Identification meliputi penemuan viewpoint. Viewpoint Documentation meliputi cara untuk mendeskripsikan setiap viewpoint dan layanan yang ditentukan sebelumnya. Viewpoint analyse and specification tahap akhir yang menganalisa kebutuhan setiap viewpoint yang didokumentasikan, setelah itu dilakukan spesifikasi dengan menggunakan matrix untuk menghubungkan setiap viewpoint dengan kebutuhan yang didokumentasikan sebelumnya.

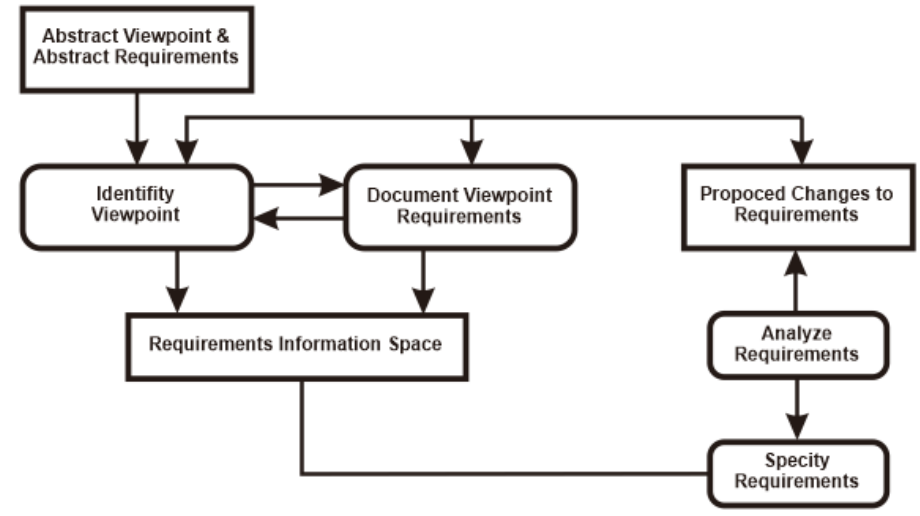

Gambar 5. Alur Proses VORD

\section{Hasil dan Pembahasan}

Metode Viewpoint Oriented Reqruiment Definition (VORD) adalah salah satu metode untuk menganalisis kebutuhan sistem dengan menggunakan pendekatan viewpoint. VORD terfokus pada entitas ekternal yang berinteraksi dengan sistem dan merepresentasikan kebutuhan dari sistem berdasarkan entitas viewpoint. Viewpoint terbagi menjadi direct viewpoint dan indirect viewpoint. Direct viewpoint menggambarkan tentang entitas yang berkorespondensi secara langsung dengan pelanggan. Sedangkan indirect viewpoint menggambarkan entitas yang berkepentingan untuk menerima service dari sistem namun tidak berinteraksi langsung dengan sistem. VORD memiliki tahapan yaitu pertama identifity viewpoint, layanan, input data, nonfunctional requirement and control events, kedua allocate to viewpoint, ketiga organize the viewpoint into a hierarchy, keempat menambahkan template dari viewpoint dan layanan dan terakhir dokumen [13].

Use case diagram aplikasi terdiri dari hak akses, menu pengajuan, menu transaksi, menu laporan, menu master, menu grafik dan menu pengaturan. Berdasarkan Gambar 6. Use Case Hak Akses. Terdiri dari Admin, Ketua, Sekretaris, Bendahara, Kasir dan Pendaftaran serta setiap user memiliki hak akses yang berbeda. Hak akses posisi admin, sudah pasti dalam melakukan akses secara penuh dalam proses menjalankan aplikasi. Hak akses posisi ketua, dapat melakukan akses menu grafik, transaksi, master, laporan dan pengajuan. Hak akses posisi 
sekretaris, dapat melaukan akses menu grafik, master, laporan dan pengajuan. Hak akses posisi bendahara, dapat melakukan akses menu transaksi, grafik dan laporan. Hak akses posisi kasir, dapat melakukan akses menu transaksi dan laporan. Sedangkan hak akses posisi pendaftaran, dapat melakukan akses menu pengajuan, laporan dan grafik

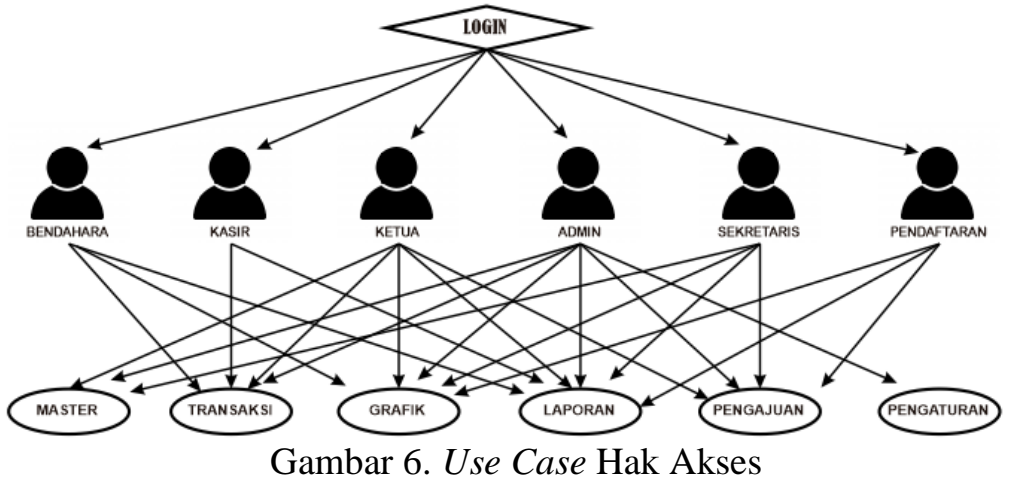

Berdasarkan Gambar 7. Use Case Pengajuan dan Transaksi. Use case pengajuan akan menampilkan Buat Pengajuan untuk calon kelompok baru pada BKAD Satria Mandiri dan mengisi form pengajuan terdiri dari nama desa asal, nama kelompok, nama ketua kelompok, nomor handphone, total pinjaman, jatuh tempo dan lainnya atau bisa masuk ke Menu Nama Desa. Sama seperti pada menu Buat pengajuan, namun perbedaanya adalah tidak perlu mengisi kolom nama desa asal karena sudah terisi secara automatis. Setelah melakukan pengisian form pengajuan akan tersimpan sementara pada Menu Master. Sedangkan use case Transaksi, akan menampilkan pencarian dan nama desa. Mencari kelompok dapat menggunakan nomor identitas kelompok atau nama ketua. Selanjutnya akan muncul tampilan nama kelompok kemudian terdapat Button Angsur untuk melakukan angsuran kredit. Cara lain menggunakan Button Nama Desa yang terdapat pada tampilan Menu Transaksi, selanjutnya muncul nama kelompok pada desa yang dipilih dan klik Button Angsur.

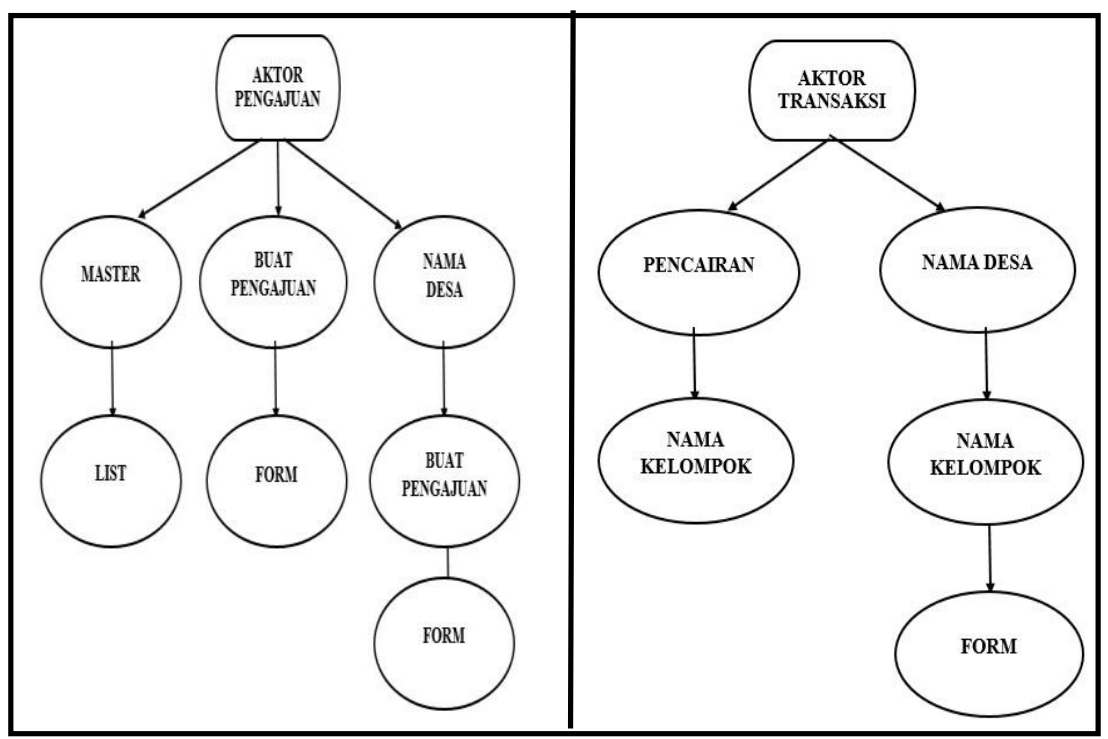

Gambar 7. Use Case Pengajuan dan Transaksi 
Berdasarkan Gambar 8. Use Case Diagram Aplikasi, ketua kelompok dapat melakukan pendaftaran, menerima bukti pinjaman, melakukan transaksi angsuran, menerima bukti angsuran. Bagian Kredit melakukan verifikasi, menyimpan arsip, membuat bukti pinjaman, menerima bukti pinjaman, membuat laporan pinjaman, menerima transaksi data angsuran, arsip data angsuran, membuat bukti angsuran, membuat laporan angsuran. Ketua UPK menerima Laporan Pinjaman dan menerima laporan angsuran. Sedangkan Admin dapat mengetahui yang dilakukan ketua kelompok, bagian kredit dan ketua UPK seperti pendaftaran, verifikasi, menyimpan arsip, membuat bukti pinjaman, menerima bukti pinjaman, membuat laporan pinjaman, menerima laporan pinjaman, transaksi angsuran, menerima transaksi data angsuran, arsip data angsuran, membuat bukti angsuran, menerima bukti angsuran, membuat laporan bukti angsuran, menerima laporan angsuran.

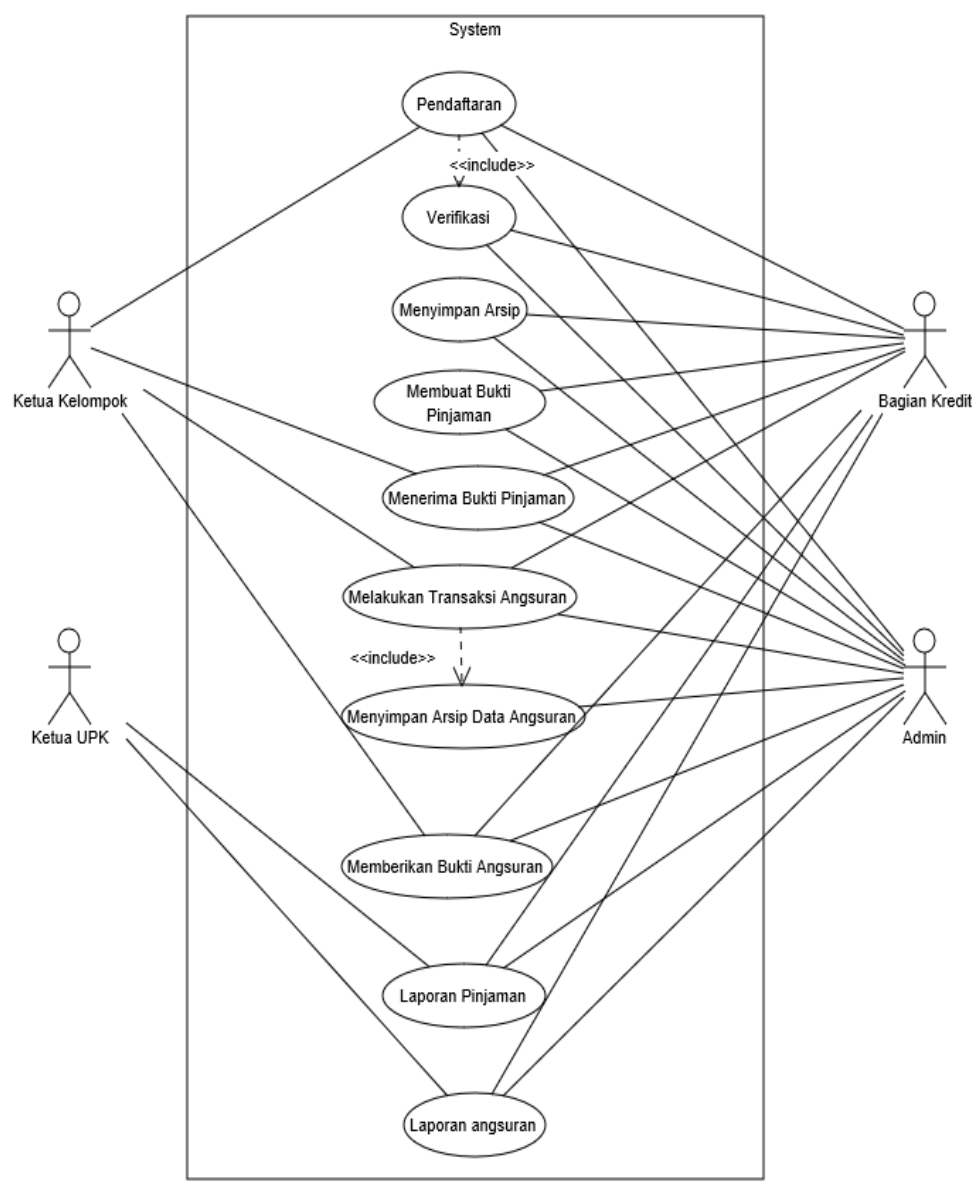

Gambar 8. Use Case Diagram Aplikasi

Berdasarkan Gambar 9. Activity Diagram Aplikasi, Ketua Kelompok dapat melakukan pendaftaran, menerima bukti pinjaman, transaksi angsuran, menerima bukti angsuran. Bagian Kredit memiliki tugas untuk melakukan verifikasi pengajuan, menyimpan arsip, membuat bukti pinjaman, menerima bukti pinjaman, membuat laporan pinjaman, menerima transaksi data angsuran, arsip data keuangan, membuat bukti angsuran, serta membuat laporan bukti angsuran. Ketua UPK dapat menerima laporan pinjaman dan laporan angsuran. Sedangkan Admin bisa mengetahui yang dilakukan ketua kelompok, bagian kredit, dan ketua UPK seperti pendaftaran, verifikasi berkas, menyimpan arsip, membuat bukti pinjaman, menerima bukti pinjaman, 
membuat laporan pinjaman, menerima laporan pinjaman, melakukan transaksi angsuran, menerima transaksi data angsuran, membuat arsip data angsuran, membuat bukti angsuran, menerima bukti angsuran, membuat laporan bukti angsuran serta melihat laporan angsuran.

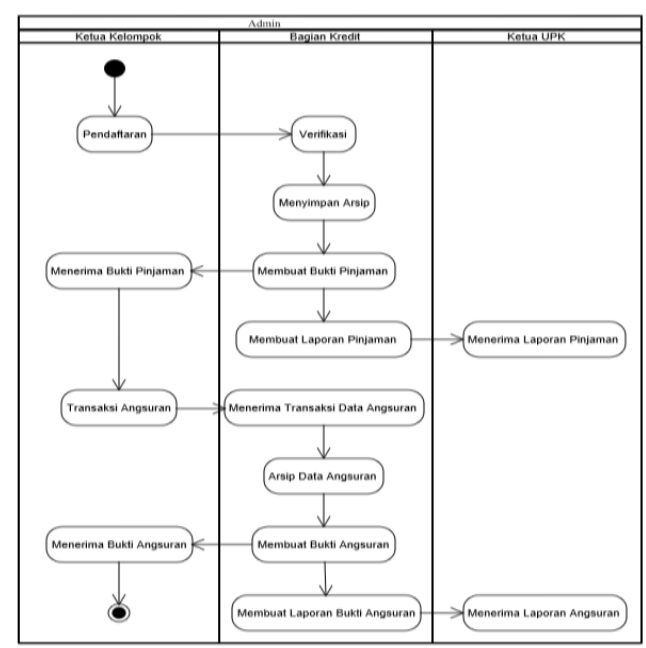

Gambar 9 Activity Diagram Aplikasi

Pada Gambar 10. Sequence Diagram Aplikasi, ketua kelompok melakukan pendaftaran ke bagian kredit untuk verifikasi, admin akan menyimpan arsip, admin membuat bukti pinjaman yang diserahkan ke bagian kredit, memberikan bukti pinjaman ke ketua kelompok, bagian kredit meminta admin membuat laporan pinjaman kemudian ketua UPK menerima laporan pinjaman, ketua kelompok melakukan transaksi angsuran ke bagian kredit, menerima transaksi data angsuran dan menyimpan data angsuran serta membuat bukti angsuran, ketua kelompok menerima bukti angsuran, dan admin membuat laporan bukti angsuran dan ketua UPK menerima laporan angsuran

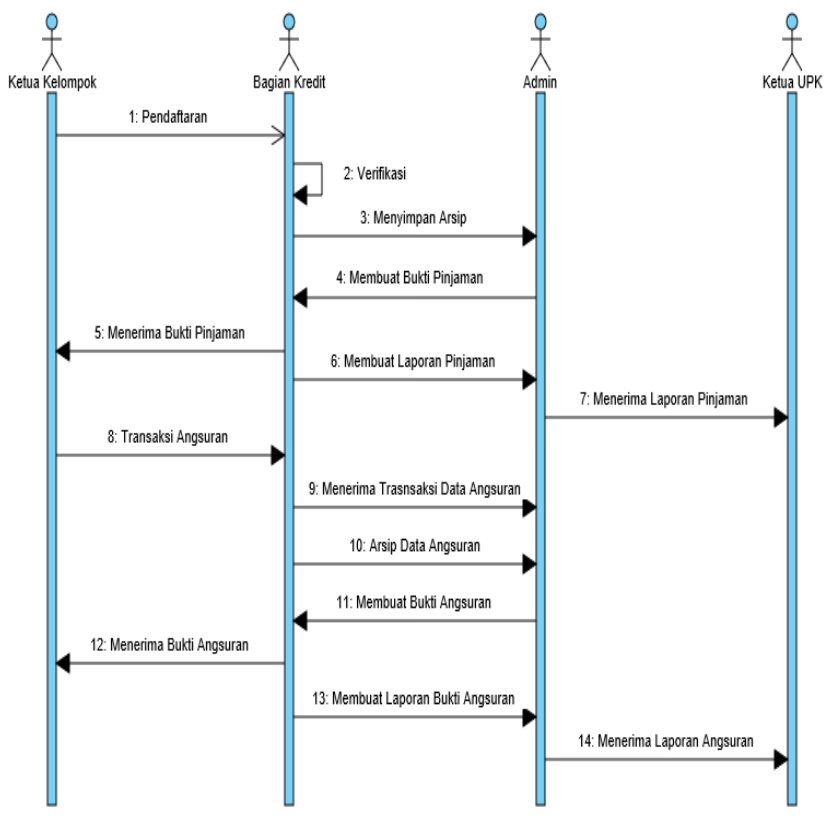

Gambar 10. Sequence Diagram Aplikasi 
Desain aplikasi menyesuaikan hasil use case diagram yang sudah dirancang sebelumnya. Aplikasi nantinya membantu proses kegiatan bisnis dari BKAD Satria Mandiri untuk lebih efisien dan efektif dalam bekerja. Berdasarkan Gambar 11. Tampilan Menu Utama, terdapat menu menu yang akan digunakan dalam kegiatan proses bisnis dari BKAD Satria Mandiri seperti Pengajuan, Transaksi, Laporan, Grafik, Master Data dan Pengaturan.

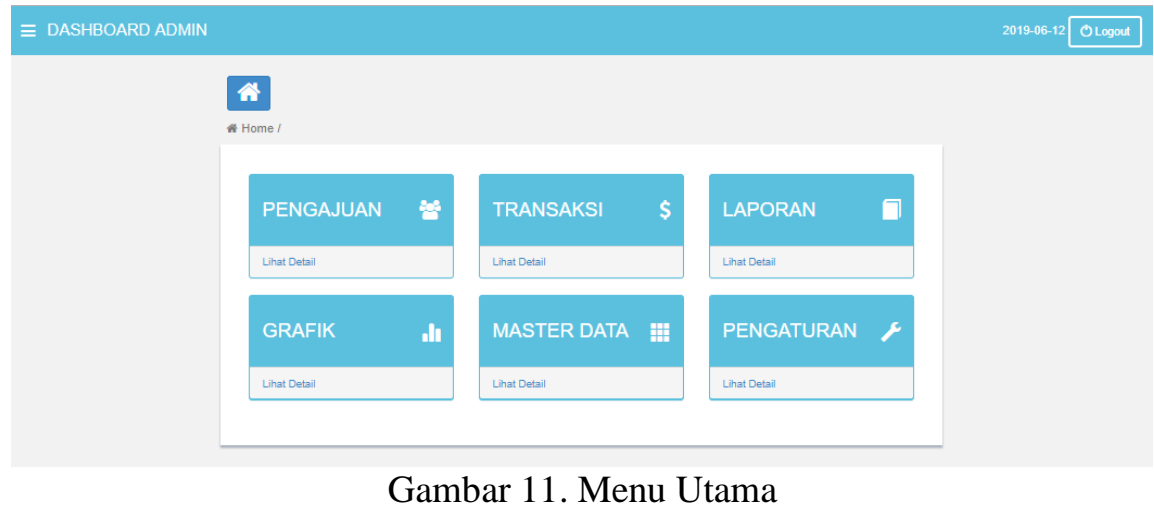

Terdapat Button Nama Desa, Buat Pengajuan dan Master Pengajuan pada Gambar 12. Menu Pengajuan. Proses pengajuan dapat diakses menggunakan Button Buat Pengajuan kemudian mengisi form pengajuan secara sistem atau memilih salah satu nama desa kemudian mengisi form pengajuan, perbedaanya adalah apabila memilih salah satu nama desa. Maka, textbox pada nama desa asal automatis terisi. Proses utamanya adalah melakukan proses input data kelompok sesuai proposal pengajuan peminjaman.

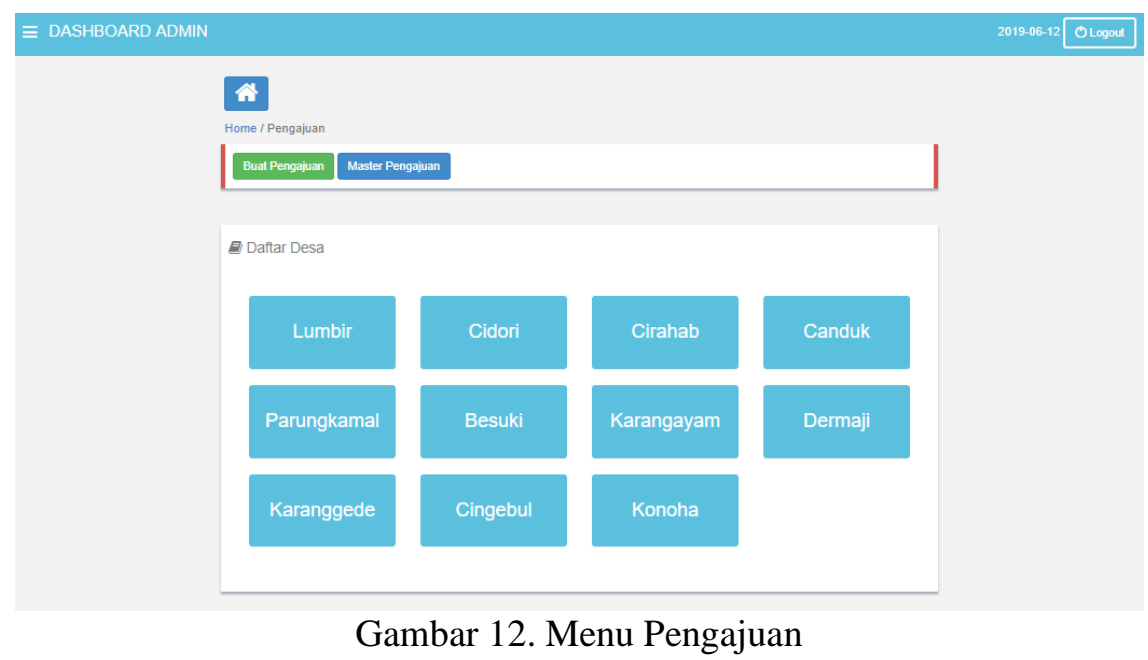

Sedangkan form pengisian data proposal berisi kode kelompok, nama desa, nama kelompok, ketua kelompok, bidang usaha, jenis simpanan, besar simpanan, lama pinjaman, alamat peminjam, nomor handphone, dan identitas anggota. besaran total kelompok melakukan peminjaman senilai Rp 5.000.000,- untuk kelompok yang baru terdaftar sebagai anggota BKAD Satria Mandiri, sedangkan kelompok yang sudah pernah melakukan peminjaman bernilai Rp 50.000.000,-. Sebagai contohnya dapat dilihat pada Gambar 13. Form Pengajuan Peminjaman. 


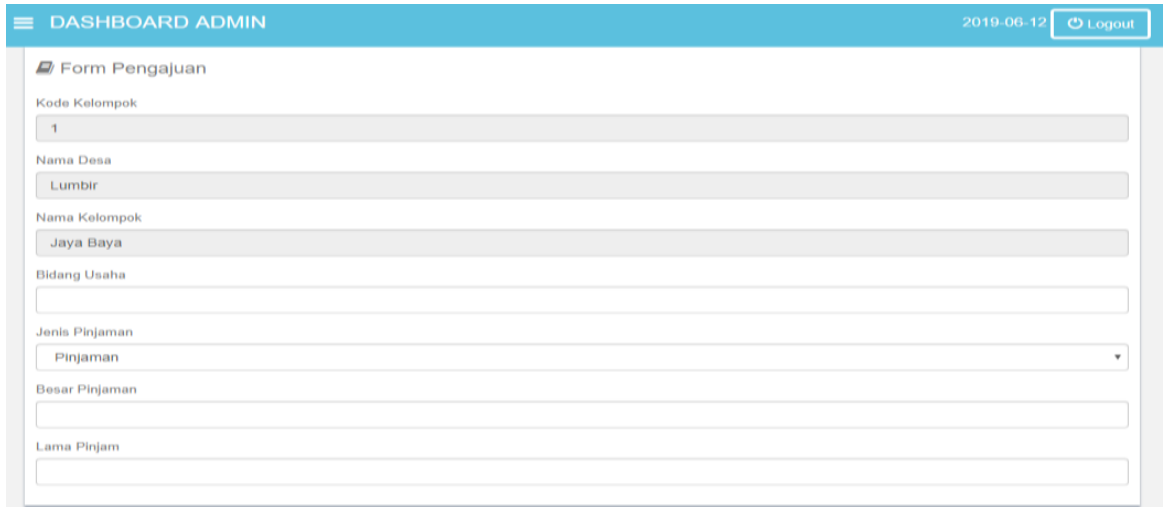

Gambar 13. Form Pengajuan Pinjaman

Tampilan form angsuran berisi kode kelompok, nama desa, nama kelompok, ketua kelompok, angsuran kredit, denda, bunga, jatuh tempo, nominal yang akan dibayar. Sebagai contoh tampilannya seperti pada Gambar 14. Form Angsuran Kredit. Proses utama dari menu transaksi adalah melakukan transaksi kredit yang sudah menjadi kewajiban setiap kelompok apabila proposal peminjaman disetujui oleh ketua BKAD Satria Mandiri.

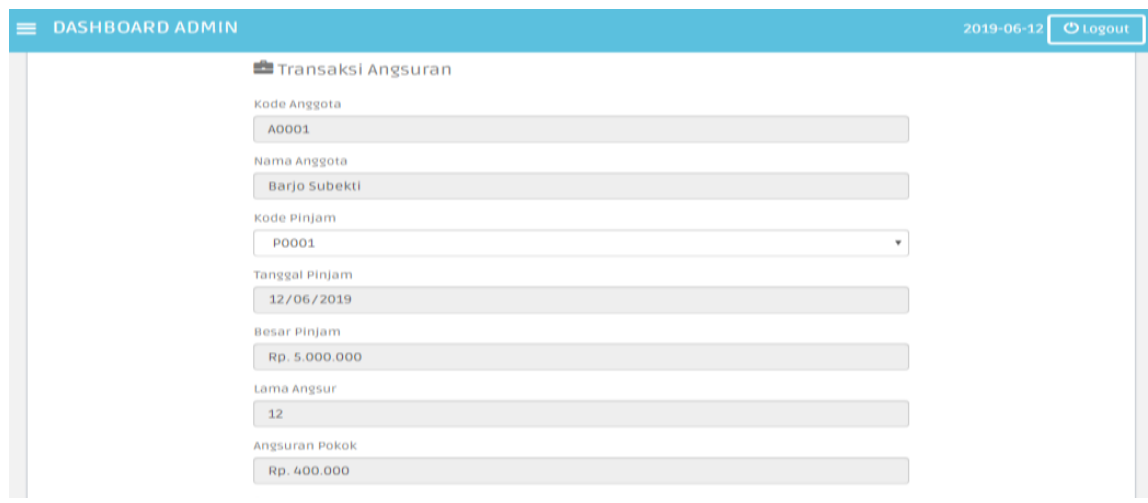

Gambar 14. Form Angsuran Kredit

\section{Kesimpulan}

Kesimpulan dari penelitian ini adalah dengan menggunakan metode Viewpoint Oriented Requierement Definition menghasilkan aplikasi yang diberi nama Shambatan Application yang artinya aplikasi yang terintegrasi untuk menyelesaikan tugas dari setiap karyawan BKAD Satria Mandiri khususnya Sekretaris, Bendahara dan Tim Survey, hal ini juga menjadi tujuan utama dari aplikasi mampu meringankan tugas dari BKAD Satria Mandiri untuk menyalurkan dana bantuan kepada masyarakat desa lebih optimal dari sebelumnya. Shambatan Application menampilkan kelompok yang mendapatkan bantuan dana dari BKAD Satria Mandiri masuk kategori Sangat Rajin atau Buruk Sekali dengan istilah kolektibilitas, artinya tepat waktu dalam melakukan angsuran kredit masuk Kolektibilitas 1. Kelompok yang melakukan 2 sampai 3 kali tunggakan, masuk Kolektibilitas 2. Kelompok yang melakukan 4 sampai 5 kali tunggakan, masuk Kolektibilitas 3. Kelompok yang melakukan 6 sampai 7 kali tunggakan, masuk Kolektibilitas 4. Kelompok yang melakukan lebih dari 8 kali tunggakan, masuk Kolektibilitas 5 dan apabila kelompok tersebut masuk Kolektibilitas 4 sampai 5 akan kesulitan mendapatkan dana bantuan kembali karena dinilai buruk.

eISSN: 2477-3255, pISSN: 2086-4884 https://doi.org/10.31849/digitalzone.v10i2. 3139 


\section{Daftar Pustaka}

[1] N. Hidayah, "Analisis Kinerja Keuangan Pada Koperas Serba USaha Bina Usaha Di Kabupaten Gowa, “Skripsi, Makasar, Universitas Negeri Makasar, 2016.

[2] I. G. P. G. P. Isa., dan Hartawan, "Perancangan Aplikasi Koeprasi Simpan Pinjam Berbasis Web (Studi Kasus Koperasi Mitra Setia), “ Jurnal Ilmiah Ilmu Ekonomi, vol. 5, no, 10, p. ISSN: 2088-6969, 2016.

[3] R. Ahmad, La Ode Ismail., dan Sinen, "Penerapan Sistem Informasi Manajemen Pendidikan Dalam Proses Pembelajaran Di SMP Negeri 21 Makasar," J. Idaarah, vol. 1, no. 2, 2017.

[4] A. Faizal, "Perancangan dan Implementasi Sistem Informasi Manajemen Simpan Pinjam Pada Koperasi Pegawai Republik Indonesia Universitas Negeri Padang (KPRI-UNP) Berbasis Web dan SMS Gateway, "Naskah Publ. Fakultas Teknik Universitas Negeri Padang, 2016.

[5] M. N. Ariani., dan Utomo, "Kajian Strategi Pengembangan Usaha Mikro Kecil dan menengah (UMKM) Di Kota Tarakan,” J. Organ. dan Manaj., vol. 13, no. 2, 2017.

[6] E. D. dan S. A. Suryaningsih, "Pengaruh Kualitas Pelayanan Terhadap Kepuasan Anggota KJRS KUM3 Rahmat Surabaya,” J. Ekon. Islam, vol. 1, pp. 55-54, 2018.

[7] R. I. G. P. Aryantha, "Analisis dan Perancangan Sistem Koperasi Simpan Pinjam Di Koperasi Monang Maning Menggunakan Visual Studio C\#.Net,” Naskah Publ. STMIK AMIKOM Yogyakarta, 2010.

[8] T. Desyani, "Perancangan Sistem Pembayaran Elektronik Berbasis Radio Frequency Identification (RFID) pada Waserda Karyawan PT. Multi Karya Usaha," J. Teknol. Sist. Inf. dan Apl., vol. 1, p. ISSN: 2654-3788, 2018.

[9] Y. R. Ramadhani., dan Lantin, "Sistem Informasi Simpan Pinjam Berbasis Website Koperasi RikRik Gemi SMKN 15 Bandung," J. Informatika., vol. 3, no. 2 p. ISSN: 2355-6579, 2016

[10] S. Alvisha Farrasita Istifani., dan., "Rancang Bangun Aplikasi Koperasi Simpan Pinjam Dengan Metode Viewpoint Oriented Requirement Definition," J. Sisfo, vol. 7, no. 2, 2018.

[11] Sugiyono, Metode Penelitian Kuantitatif, Kualitatif R\&D. 2017.

[12] I. Sommerville, "Viewpoints For Requirements Engineering," no. September, 2013.

[13] M.B. Wibawa, "Pengayaan Metode Viewpoint Oriented Requierement Definition dengan CMII dan Metode Proto Personas untuk analisis Kebutuhan, "Thesis, Depok, Universitas Guna Darma, 2014. 